\title{
Water-Transit Services in Dubai-UAE: User and Operator Survey Development and Quantitative Analysis
}

\author{
Mohammad Nurul Hassan, Yaser E. Hawas, Faisal Ahmed, \\ Munjed Maraqa, and Md Bayzid Khan \\ UAE University
}

\begin{abstract}
The Marine Agency-Roads and Transport Authority (MA-RTA) of Dubai-UAE is currently undertaking a study to develop a new transport policy for service delivery. The goal of the new policy is to increase rider share and use of MA-RTA services. To attain this goal, a five-year service policy will be adopted to establish modern, cost-effective, and efficient services to attract higher ridership. An integral part of the development of the policy is to assess baseline conditions, particularly user and operator opinions of current services. This paper focuses on developing user and operator survey questionnaires and providing quantitative statistical analyses of survey results. The majority of the assessment tools for the operations practice indicated acceptable levels of services. However, there is a need for a reduction of trip fares, better facilities at the stations, and a broader survey to identify prospective users and attraction methods to the marine services. In addition, development of a database for the marine transport system could assist in better planning, operational, and management aspects of the system.
\end{abstract}




\section{Introduction}

The Marine Agency-Roads and Transport Authority (MA-RTA) of Dubai-UAE is currently developing its service delivery policy. The overall goal of the new policy is to increase the rider share or use of MA-RTA services and to provide quality marine transport services that meet the needs of the riding public. To attain that goal, MA-RTA will adopt a five-year service policy for the establishment of modern, cost-effective, and efficient services to attract higher ridership. Several previous studies showed how ferry services could be financially viable (Ceder 2006; Melissa and Michael 2007). Furthermore, Lai and Lo (2004) developed a ferry fleet management model and solution algorithm to optimize ferry fleet size, ferry routing, and service schedules for both direct and multi-stop services in Hong Kong.

MA-RTA has two types of public marine transport services in Dubai Creak: Abra and Waterbus. These two marine transport modes share some characteristics, but differ mainly in the comfort level of service, fare, and loading or capacity utilization. Some basic information of these services is listed in Table 1. Abra service is operated by individual operators in two routes (R1 and R2 in Figure 1). Waterbuses are operated by a private firm on four routes (B1-B4 in Figure 1). Nonetheless, MARTA oversees all marine services by setting legislation, operation codes, planning services, and licensing.

An integral part of the development of the service policy of MA-RTA is to involve the public in the planning process in a consistent, fair, and thorough manner (MBTA 2006). Moreover, system monitoring and feedback are critical components in the planning and decision making processes (Pickrell and Neumann 2000). No study has been conducted to assess the current conditions of marine transport services in Dubai. Thus, one of the objectives of this study was to assess the baseline performance of MA-RTA services and suggest measures for higher efficiency. Odeck and Brathen (2009) conducted a similar type of study in Norway to demonstrate the performance evaluation and improvement of ferries serving the road network. These authors presented causes of inefficiency and ways to improve the system.

In general, the literature on issues of relevance to water-transit operations and planning is rather limited and quite diverse. Predicting ferry ridership historically has been difficult because water-transit riders often choose their travel mode based on factors other than travel time and cost (Outwater et al. 2003). Watertransit has been addressed as an element of the overall intermodal connectivity matrix (Russell and Eugene 1999). Issues of intermodal connectivity were par- 
Table 1. Basic Information on MA-RTA Services ${ }^{1}$

\begin{tabular}{|c|c|c|c|c|c|c|c|}
\hline Route & $\begin{array}{c}\text { Station } \\
\text { Name }\end{array}$ & $\begin{array}{c}\text { Working } \\
\text { Hours }\end{array}$ & $\begin{array}{l}\text { Vessel } \\
\text { Capacity }\end{array}$ & $\begin{array}{c}\text { Number } \\
\text { of } \\
\text { Vessels }\end{array}$ & $\begin{array}{c}\text { Number } \\
\text { of } \\
\text { Operators }\end{array}$ & $\begin{array}{c}\text { Route } \\
\text { Length } \\
(\mathbf{k m})\end{array}$ & $\begin{array}{c}\text { Average } \\
\text { Daily } \\
\text { Person } \\
\text { Trips }\end{array}$ \\
\hline R1 & S1- S2 & 5am-12am & 20 & 40 & 80 & 0.55 & 10,839 \\
\hline $\mathbf{R 2}$ & S3 - S4 & $24 \mathrm{hrs}$ & 20 & 110 & 220 & 0.8 & 28,186 \\
\hline B1 & $\mathrm{S} 1-\mathrm{S} 4$ & $6 a m-11 p m$ & 36 & 1 & \multirow[t]{4}{*}{24} & 1.058 & 109 \\
\hline B2 & $\mathrm{S} 3-\mathrm{S} 5$ & $6 a m-11 p m$ & 36 & 2 & & 1.286 & 335 \\
\hline B3 & $\mathrm{S} 4-\mathrm{S} 5-\mathrm{S} 6$ & $6 a m-11 p m$ & 36 & 2 & & 1.966 & 393 \\
\hline B4 & S3 - S4 & $\begin{array}{l}12 \text { Midnight - } \\
\text { 6am }\end{array}$ & 36 & 1 & & 0.907 & 107 \\
\hline
\end{tabular}

${ }^{1}$ Legend: $\mathrm{R}=\mathrm{Abra}, \mathrm{B}=$ Waterbus, $\mathrm{S} 1=$ Bur Dubai station, $\mathrm{S} 2=$ Diera Old Souk station, $\mathrm{S} 3=$ Dubai Old Souk station, $\mathrm{S} 4=$ Al Sabkha station, $\mathrm{S} 5=$ Baniyas station, $\mathrm{S} 6$ = Al Seef station.

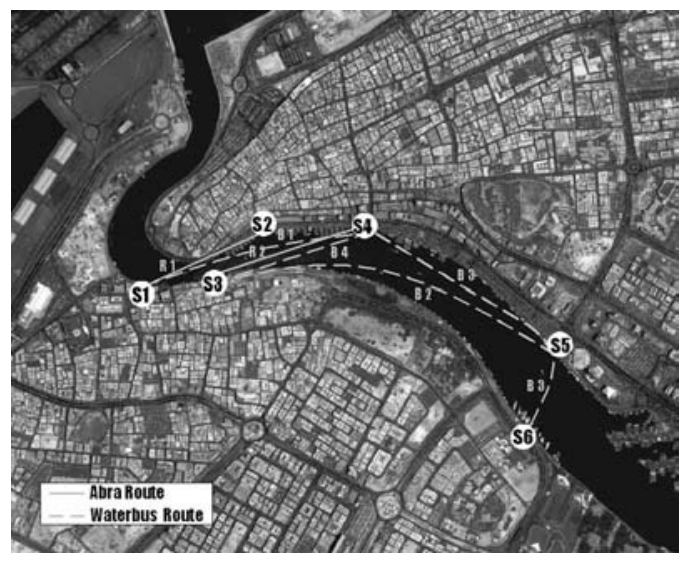

\section{Figure 1. Location of Dubai Marine Service Stations and Routes}

ticularly useful in planning ferry terminals to separate travel modes for safe and efficient travel, to minimize intermodal transfer time, and to maximize intermodal transfers of passengers from transit to ferries (Russell and Eugene 1999).

Ferry fleet management, including ferry fleet size selection, ferry routing, and service scheduling, were addressed by Lai and Lo (2004). An optimization algorithm was developed for the direct and multi-stop service in Hong Kong, using both operator and passenger performance measures. 
Recent market developments facing the European ferry industry, including competition and safety-related implications, are addressed in the study by Dunlop (2002). The growing interest in waterborne transit in Florida has been addressed by Wilson (2005). An overview of how key local players initiated regular ferryboat service was provided. The role of coordination among federal, state, and regional transportation authorities has been appraised in contributing to the growth of waterborne transit in Florida.

\section{Survey Design Process}

The survey design adopted here was the "stated preference survey." In this type of survey, respondents are placed in hypothetical choice situations and asked what they would do if they were faced with a particular choice (Polak and Jones 1995; Espino et al. 2007; Ahern and Tapley 2008). Two different types of survey were conducted, one for users (customers) and the other for operators of the vessels.

The user survey form provides the stated preference of the responses in terms of service characteristics, accessibility, and marine transport station facilities. The questions are designed to capture the (1) socioeconomic characteristics in terms of gender, age, level of education, and personal (family) income and (2) factors affecting the choice of modes for connecting trips, the purpose of the trips, the possibility of switching to an alternative mode or unwillingness to pay increased trip fares, the origin and destination of their regular travel patterns, general satisfaction level regarding the service, and problems/suggestions in using the infrastructure facilities.

Substantial efforts were invested in ensuring that the relevant information on preferences was elicited with fewer questions. The on-site survey method was used as it allows the interviewer to elaborate on the marine transport characteristics as well as personally interview the respondents. This enabled respondents to make more informed "stated preference" decisions on the marine transport and increased the reliability of the responses. An on-board survey was adopted in this study. The population of the survey represents actual MA-RTA services users, but does not include non-users (or prospective users). Extension of the survey to marine service non-users could be the subject of a future study.

Aiming at accounting for operator opinions in developing MA-RTA policy, and to balance between user and operator satisfaction, the views of the operators of the Waterbus and Abra with regard to day-to-day problems, working schedules, and 
concerns, as well as suggested recommendations to improve the marine transport systems, all were captured via a separate operator survey form.

The key data from the user survey include purpose of the trip, route, fare, economic ability of the user, accessibility of the modes with other land transport systems, trip travel time, frequency, comfort, safety, and user preference regarding services. Operator survey data include the experience of the operators, work schedule, workload, service satisfaction, vessel performance, and opinion on the service.

\section{Sample Size}

A simple random sampling procedure was considered. Each response, either quantitative or qualitative, of a question is considered of equal importance and has equal likelihood of selection. For distribution of responses with normal distribution, the minimum number of surveys required for a $90 \%$ confidence level is calculated by using the following formula (Miller et al., 1990):

$$
n=\frac{3.24 v^{2}}{d^{2}}
$$

where,

$n$ is the minimum sample size (number of users),

$v$ is the coefficient of variation (assumed as 0.5 ), and

$d$ is the tolerance level (assumed as 5\%).

For the user survey, the minimum sample size was estimated to be 324. A sample size of 500 was targeted to enhance the reliability and confidence level of the findings of the survey analysis. For the operator survey, it was originally planned to take a sample of 75 (the minimum number required for a $95 \%$ confidence interval with a $10 \%$ margin of error). But, due to the reluctance of the Abra operators to take the survey as well as their time constraints, only 42 samples ( 28 from Abra and 14 from Waterbus) were collected.

\section{Survey Management Process}

The survey team consisted of transport engineers, transport planners, and survey specialists. The members of the team were from different nationalities who can 
speak Arabic, English, Hindi, Urdu, Bengali, and Filipino fluently in order to communicate with users and operators more comfortably.

The preliminary survey (pilot survey) questionnaire was tested to determine if the questions were understandable, answerable, well-motivated, and useful, to check timing and response behavior. Also, the pilot survey was intended to examine whether or not the survey questions included technical jargons, were long-winded, biased, or redundant, or made the respondent uncomfortable. The questionnaire was slightly modified after the pilot survey to incorporate shortcomings.

The survey was conducted on weekdays and weekends to cover the potential variability of the service on different days as well as the various trip purposes. The survey schedule also considered hourly variations (i.e., morning and evening work hours).

As the survey management process was critical to the successful execution of the survey, survey quality control and response rate were monitored carefully. Survey quality control included recruitment and training of interviewers, supervision of survey staff, procedures for data capture and cleaning, and communications with the public.

Users at the stations were either given the survey form to fill or interviewed by a survey team member, whichever was more convenient to the user. In many instances, the survey team member boarded along with the Abra or Waterbus passengers to increase the convenience level for the users. Respondent who seemed to be of little education were interviewed by a survey team member.

\section{Quantitative Analysis}

The user and operator surveys were descriptively analysed using the combination of the SPSS statistical program and Microsoft Excel. This section highlights some of the most important findings of the analyses.

\section{User Survey}

Socio economic characteristics of users. About half of the Abra users (52\%) were had some or no education. About 13 percent were illiterate (Figure 2). Among the Waterbus users, 79 percent were graduate or post-graduate level (Figure 2). The occupation and income level data of marine service users are illustrated in Figures 3 and 4, respectively. The general worker class was the main category (75\%) among Abra users; professionals were the major users (46\%) of the Waterbus systems. More than half of the Abra users (53\%) earn AED 2000 or below per month, while 58 percent of Waterbus users earn AED 5,000 or more per month (Figure 4). 
Abra

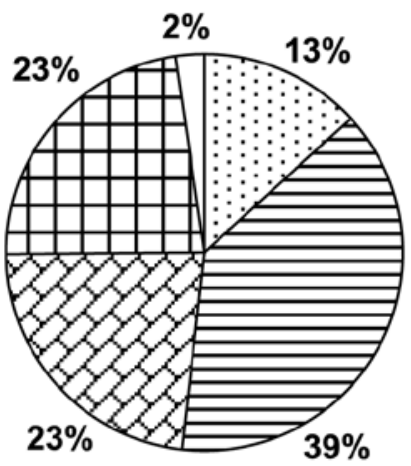

Waterbus

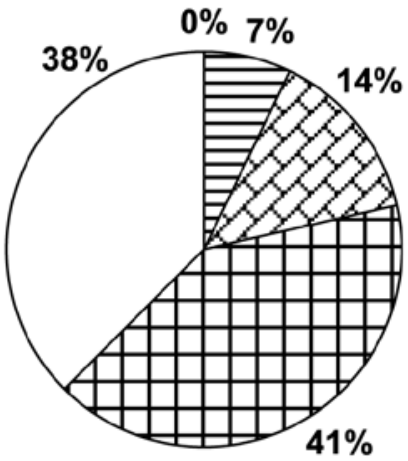

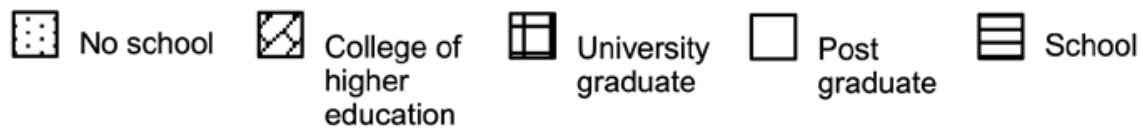

Figure 2. Education Level of Users of Marine Service
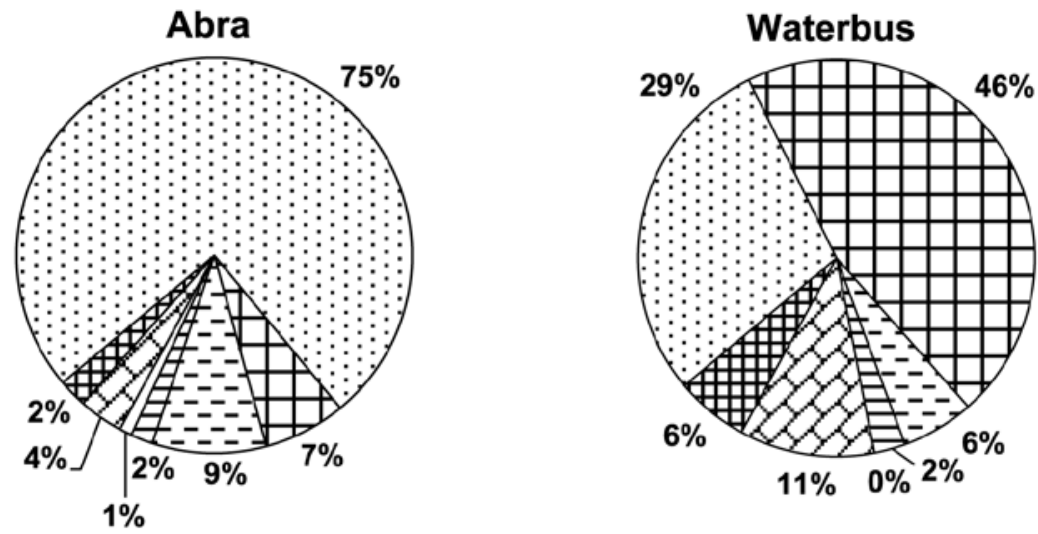

\begin{tabular}{|c|c|c|c|}
\hline $\begin{array}{l}\text { General } \\
\text { worker }\end{array}$ & $\begin{array}{l}\text { 团 Professional } \\
\text { Tourist }\end{array}$ & $\begin{array}{l}\text { E-G Businessman } \\
\square \text { Visitor }\end{array}$ & $\begin{array}{l}\text { 曲 Undisclosed } \\
\text { Others }\end{array}$ \\
\hline
\end{tabular}

Figure 3. Occupation of Users of Marine Service 
Abra

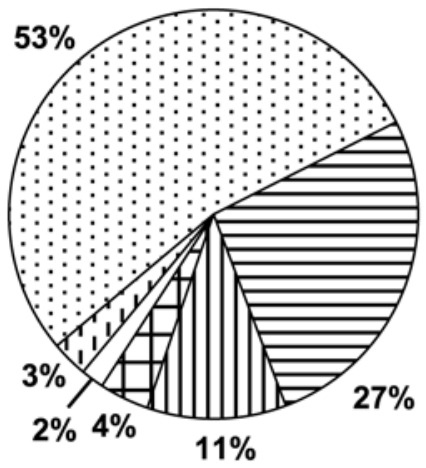

Waterbus

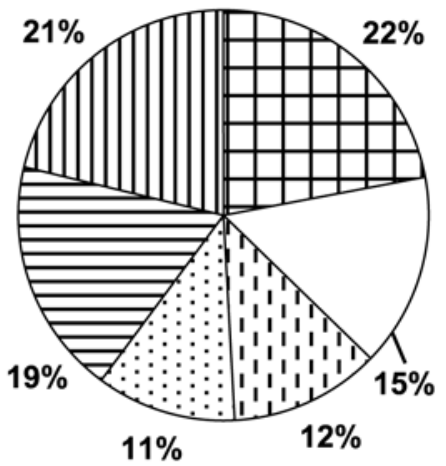

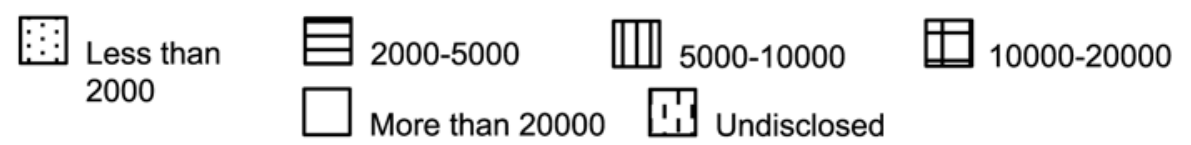

Figure 4. Income Level (AED per Month) of Users of Marine Service

These figures indicate that highly-qualified and relatively high-income groups use Waterbus services and low-income groups generally use Abra services. Such patterns could be attributed to several reasons. First, there is a difference in the fare of the two marine transport systems, with the Waterbus fare four times higher than that of Abra. Second, there are differences in the surrounding land uses of the stations. For example, S1, S2, and S3 are surrounded by traditional old market areas of Dubai, while $\mathrm{S} 5$ and $\mathrm{S} 6$ are surrounded mainly by offices and $\mathrm{S} 4$ is surrounded by a mixed use of marketplaces and offices. Third, the network itself does not allow a choice between the two modes for any destination (except for $\mathrm{S} 3$ and $\mathrm{S} 4$ from 12:00 midnight to 6:00 a.m.).

Performance of the existing system. The overall mobility rate (denoting the average number of trips per user per day) for the marine transport system (combination of Abra and Waterbus only) was 0.88 , while for the Abra system it was 0.89 , indicating more or less the same mobility characteristics for both mode users. 


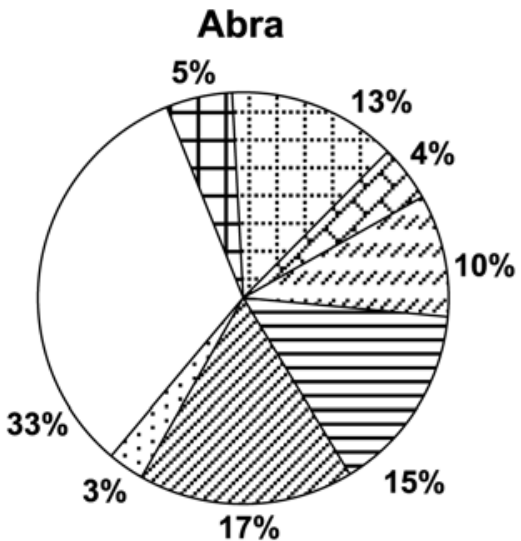

$\square$ Twice or more daily

\# Once daily

\section{筆 Several times weekly}

8 Once a week
Waterbus

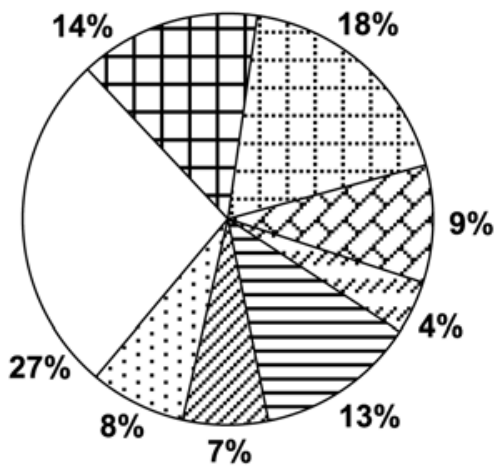

FId Several times monthly

Weekend only

Once a month

Figure 5. Frequency of Use of Marine Service

The main purpose for use of the marine transport service was work (Figure 6). About 61 percent of the marine transport users made their trips for work purposes only. On weekdays, it was 80 percent for Abra and 80 percent for Waterbus. On weekends, 22.4 percent was for Abra and 25 percent was for Waterbus. The next higher portion of trip purposes is leisure and shopping; on weekends, more than 70 percent Abra trips and 66 percent of Waterbus trips were made for these purposes. In conclusion, both modes are similar in accommodating the same trip purposes.

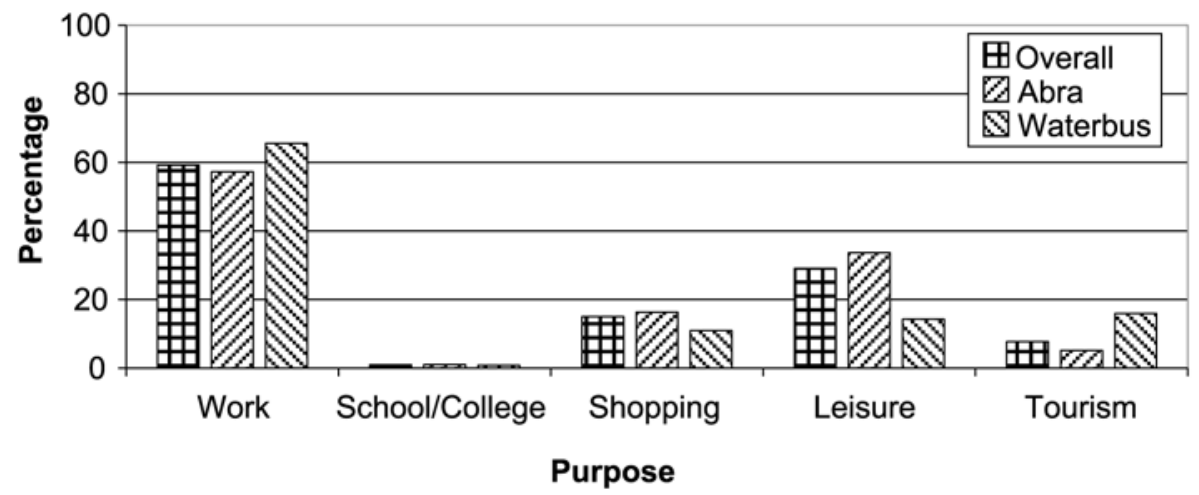

Figure 6. Purpose of Use of Marine Service 
The waiting time for Abra is less than that of Waterbus (Figure 7). About 80 percent of Abra users had to wait less than 5 minutes, and 93.3 percent had to wait for less than 10 minutes at the stations. On the other hand, 36 percent of Waterbus users wait for less than 10 minutes, and about 90 percent wait for less than 20 minutes. Waterbus service frequencies vary between $10-30$ minutes based on routes and peak hours.

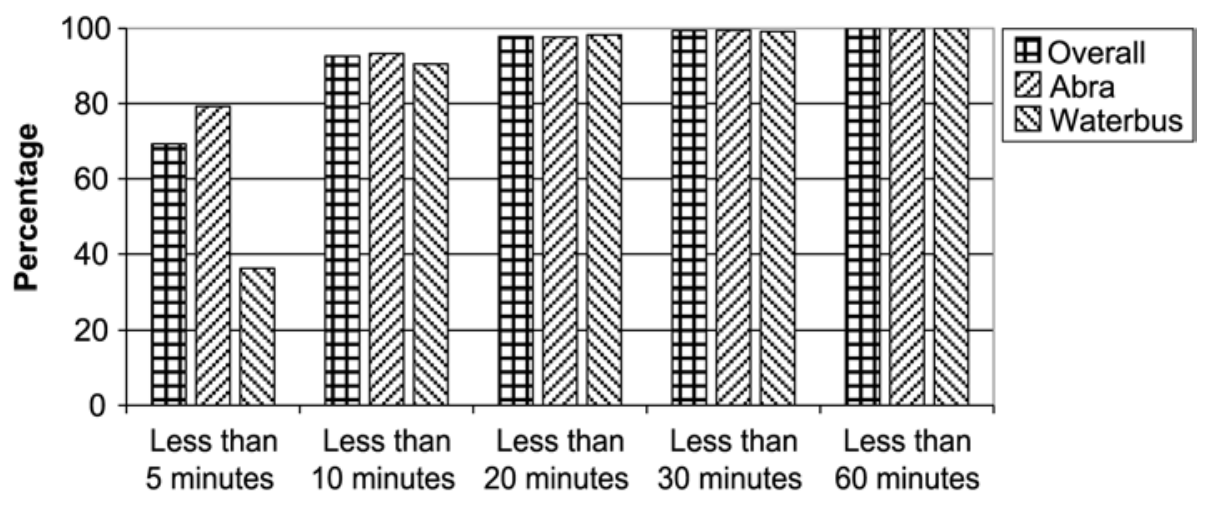

Time

Figure 7. Average Waiting Time for Marine Service

An important question to be addressed (and as such reflected in the policy) is whether higher mode utilization can be achieved by increasing the frequencies or reducing the fare of the Waterbus, especially on the shared or competing routes with Abra services.

Figure 8 illustrates the acceptable walking distance for marine service users. Only 21 percent regarded a walking distance of more than $400 \mathrm{~m}$ from/to the marine stations as acceptable. About 71 percent indicated accepting a walking distance up to $400 \mathrm{~m}$, the dominant acceptable walking distance for marine service users.

In ranking the most important criteria of service effectiveness (Figure 9), trip fare was the highest ranked, followed by safety. Trip travel time and ease of payment methods were reported to be the least important criteria of the service. 


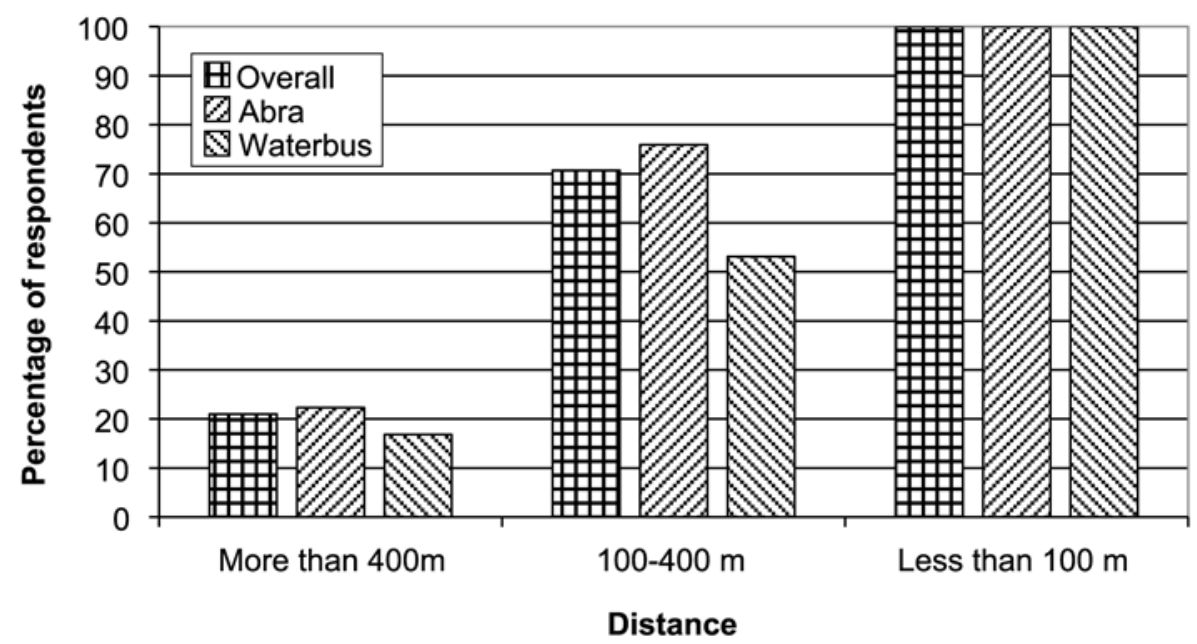

Figure 8. Acceptable Walking Distance to Marine Station

Most important criteria according to the respondants

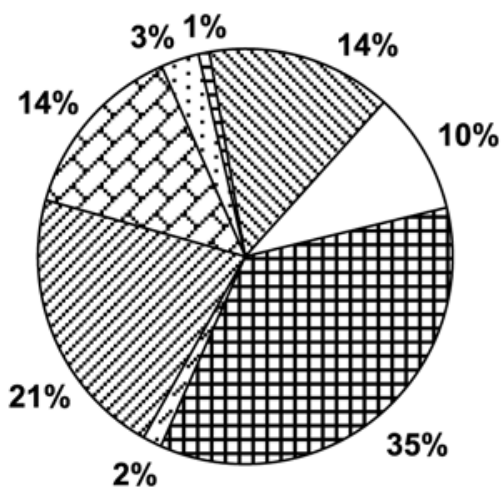

Least important criteria according to the respondants

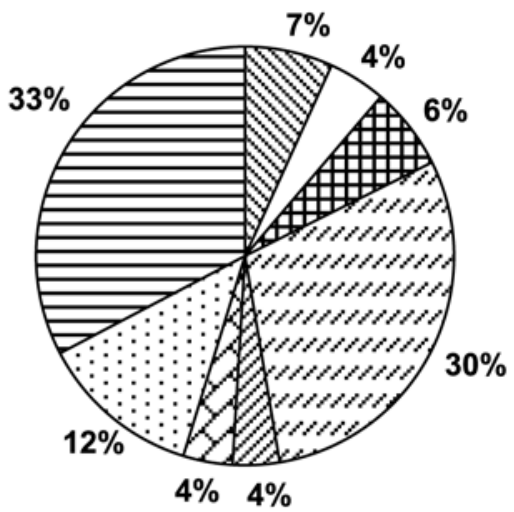
$\$$ Accessibility

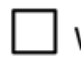
Waiting time and frequency
曲 Cost
Ease of payment
ש Safety
$\triangle$ Comfort method
$\therefore$ Time scheduling
Trip travel time

Figure 9. Most and Least Important Criteria in Ranking Service Effectiveness 
The willingness to pay a higher fare for service is reported in Figure 10. Nearly 43 percent, 25 percent, and 20 percent of the marine users indicated a willingness to pay a fare increase of 50 percent, 75 percent, or 100 percent, respectively. The reported willingness levels are a bit higher for Abra service users. As for Waterbus users, 33 percent, 15 percent, and 9 percent indicated a willingness to pay for a fare increase of 50 percent, 75 percent, and 100 percent, respectively. Apparently, the willingness levels of Waterbus users to pay a fare increase are less than those of Abra users. This can be explained by the relatively high fare of Waterbus compared to Abra.

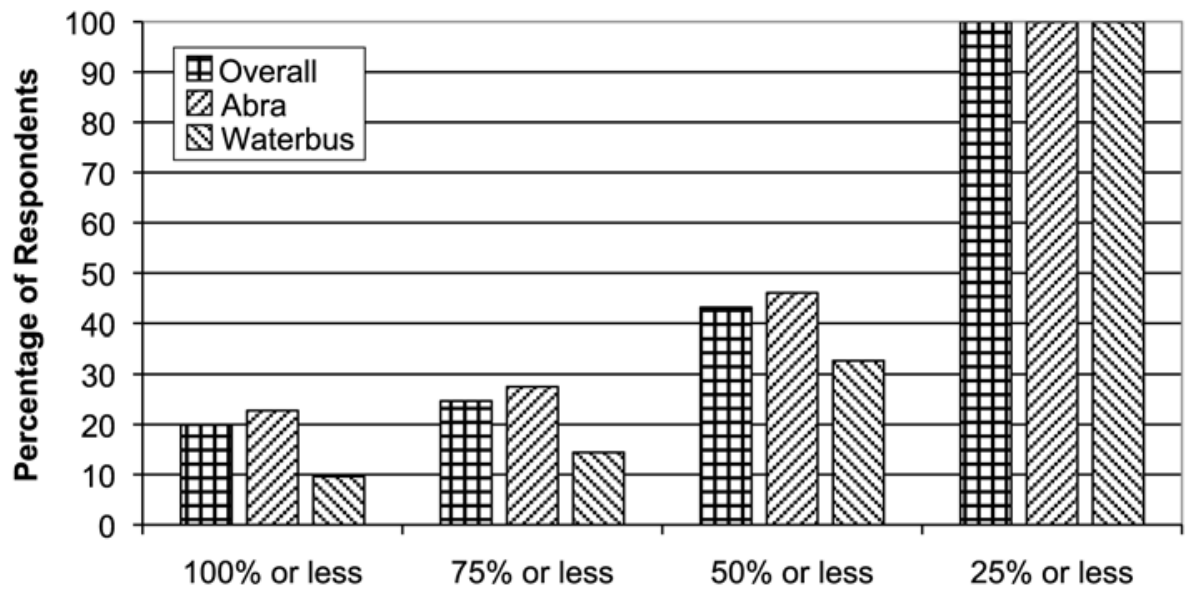

Fare Increase

Figure 10. Willingness to Pay Increased Fares

Figure 11 illustrates user satisfaction levels for the marine services. The user survey shows similar satisfaction levels for both Abra and Waterbus service. A total of 84 percent of marine service users were satisfied, 15 percent were partially satisfied, and only 1 percent were not satisfied with the service. 


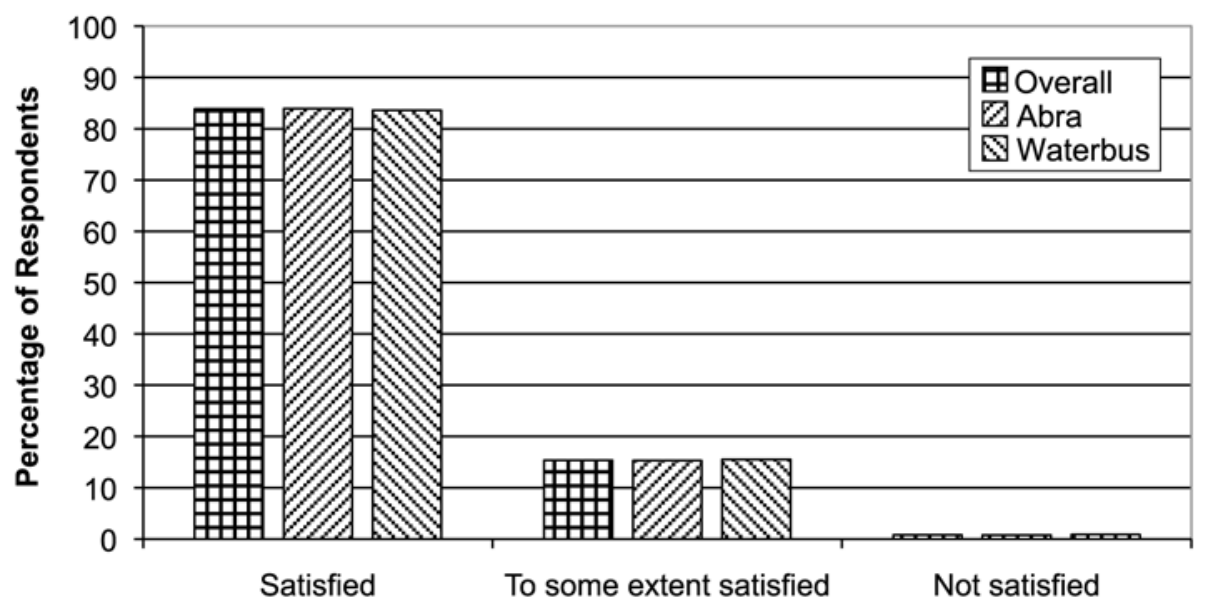

Figure 11. Satisfaction Level with the Marine Service

\section{Existing Intermodal Connectivity}

With regard to the use of other public transportation modes, Abra users indicated the use of bus and taxi, while Waterbus users indicated the use of private car and taxi (Figure 12). The cross-use percentage of Abra and Waterbus is quite minimal and insignificant; very few Waterbus users use Abra, and the use of Waterbus by Abra users is quite rare. One possible reason for this low cross-use-percentage is the rare existence (only for $\mathrm{R} 2$ and $\mathrm{B} 4$ routes) of a choice between Abra and Waterbus on different routes.

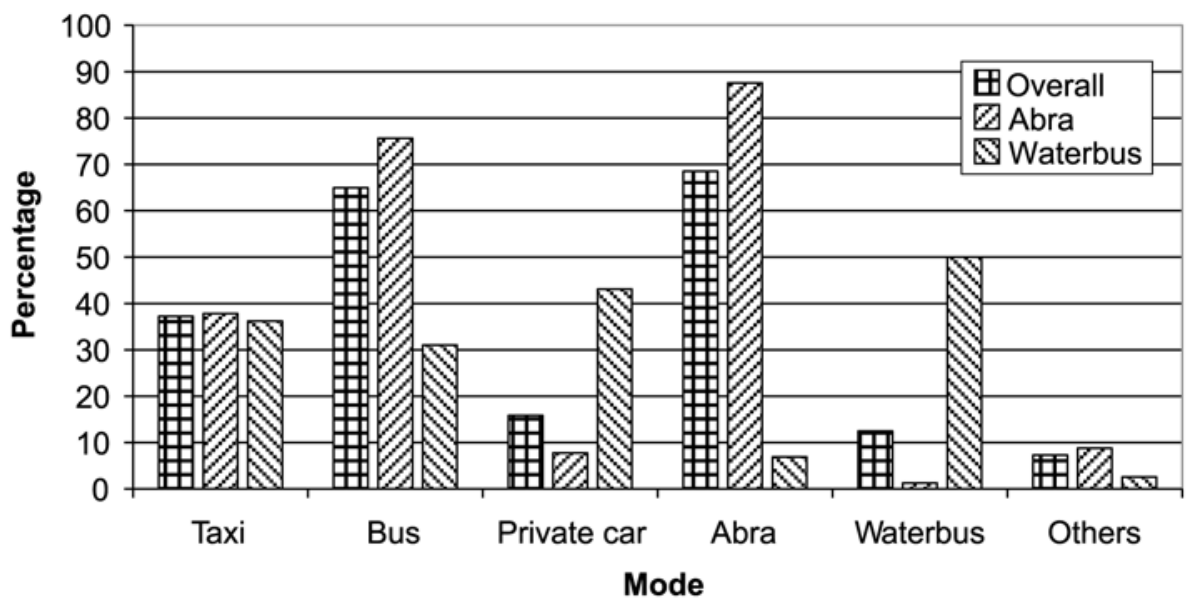

Figure 12. Mode of Transportation Regularly Used by Marine Transport Users 
Figure 13 shows the modes used by passengers to/from the marine stations. More than 55 percent of total marine service users (both Abra and Waterbus) walk to/ from the station. The percentage of bus usage varies among stations (5 - 35\%), with S2, S3, S1 and S4 the common stations entailing more bus usage (20\% or more). Taxi usage is not as common as bus, with only 5 - 10 percent of trips including taxi usage.

For all marine stations, around 40 percent of users using public transport confirmed difficulty with using land transportation modes (Figure 14). A total of 60 percent or more of users indicated some degree of difficulty at different stations. At some stations (e.g., S2), more than 80 percent of users indicated some degree of difficulty. This reveals the importance of intermodal connectivity of the marine transport services and other surface public transport modes. All stations showed problems with connectivity, especially by bus.

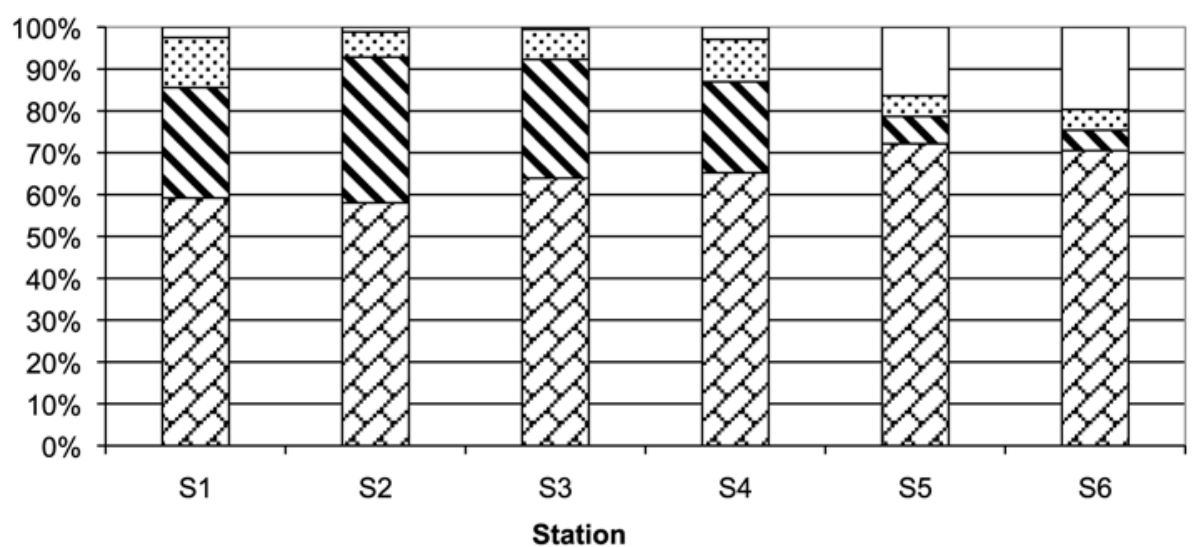

W Walking $\quad$ Bus $\quad \square$ Taxi $\quad \square$ Private Car

Figure 13. Modes of Transportation Used to Reach and Leave Marine Stations 


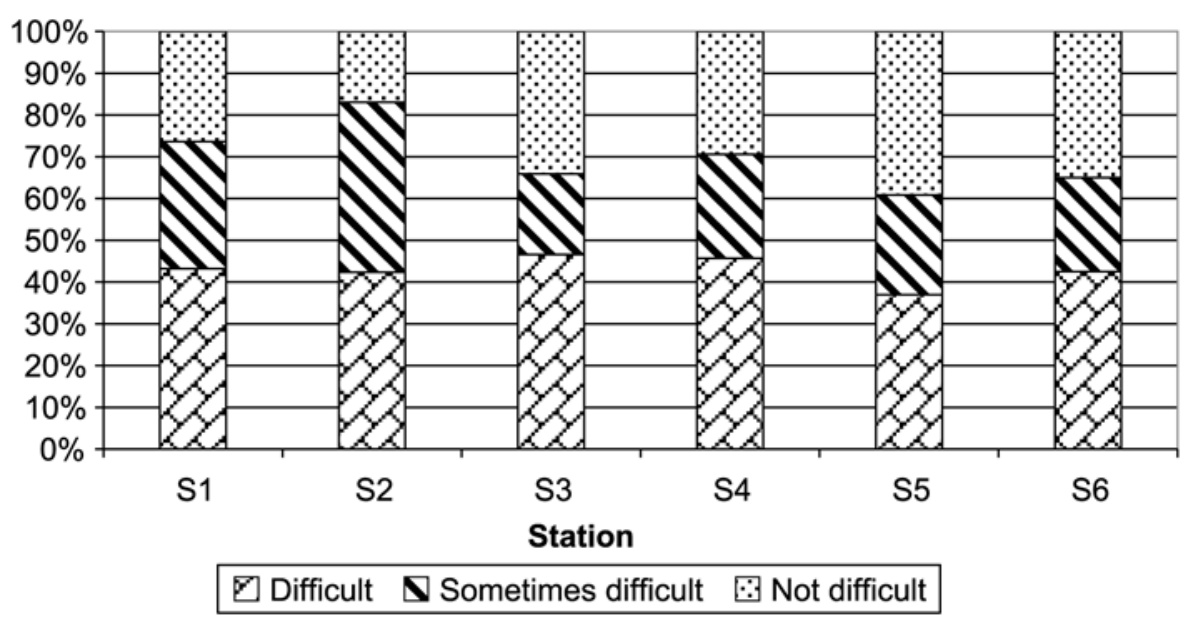

Figure 14. Availability of Public Transport (Bus and Taxi) To/From Marine Stations

\section{Operator Survey}

Most Abra operators had good experience with this mode. About 96 percent of Abra operators had more than one year of operating experience in the UAE, and 89.3 percent had the same experience with the current vessel (Figure 15). Waterbus is a relatively new mode (started in 2007). Only 41.6 percent of Waterbus operators had more than one year of experience in the UAE, and only 14.3 percent had more than one year of experience with the current vessel.

Most operators ( $85 \%$ for Abra and $100 \%$ for Waterbus) thought the service of the vessel was good or very good (Figure 16). Most Waterbus operators felt that the Waterbus is safe. However, only 68 percent of Abra operators indicated good safety levels, and 14 percent indicated acceptable levels. In general, the Abra safety level was perceived to be a bit less than that of Waterbus. 


\section{Experience of the operators in UAE}
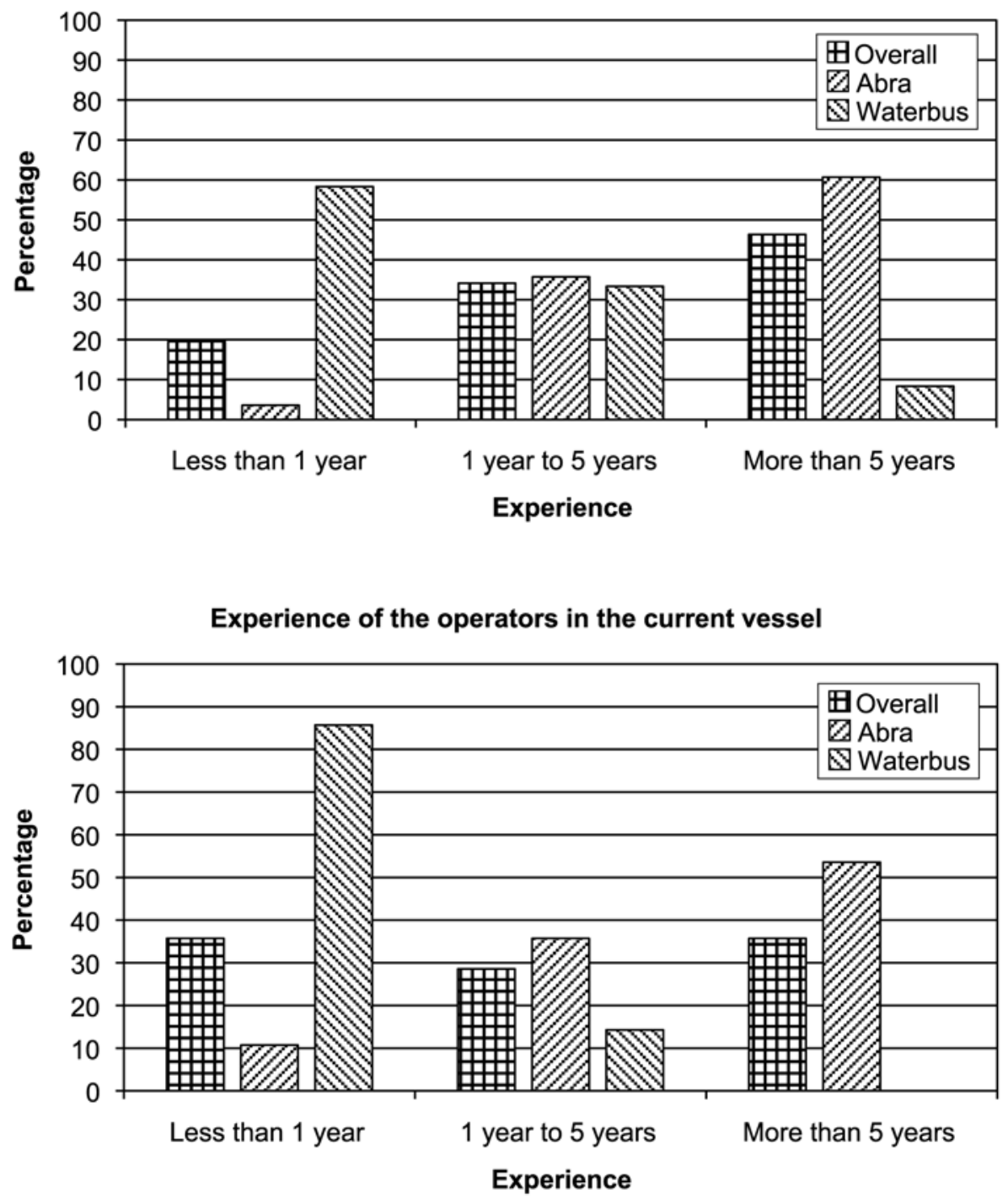

Figure 15. Experience of Marine Transport Operators in the UAE 
Level of service of the marine vessels

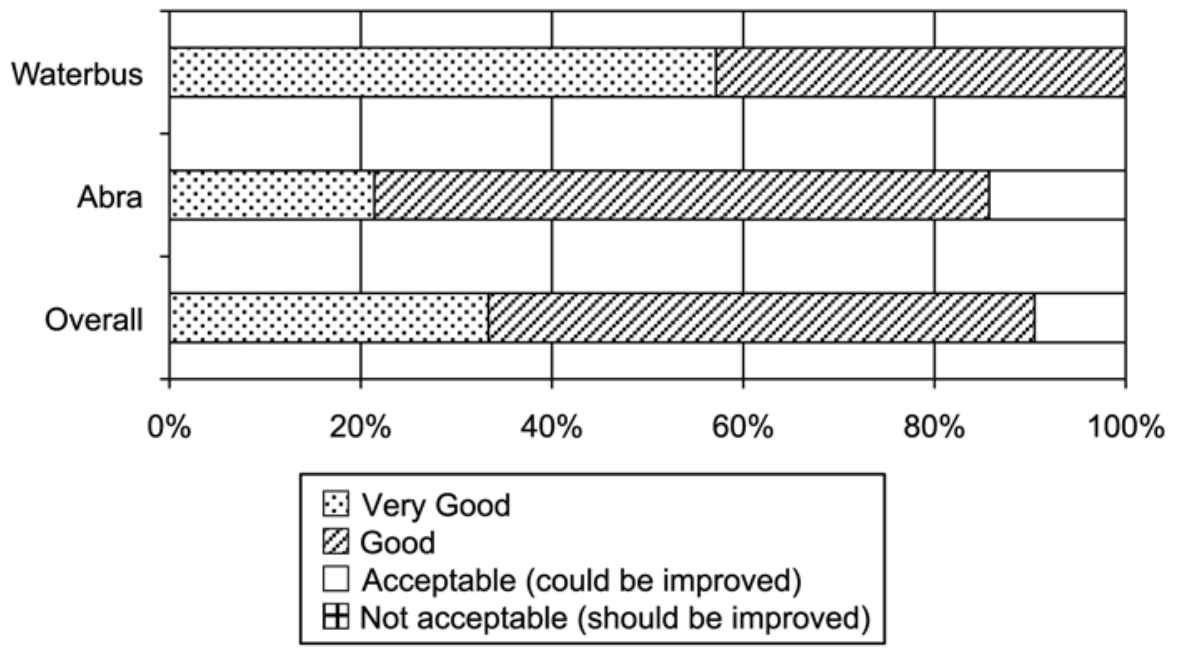

Level of safety of the marine vessels

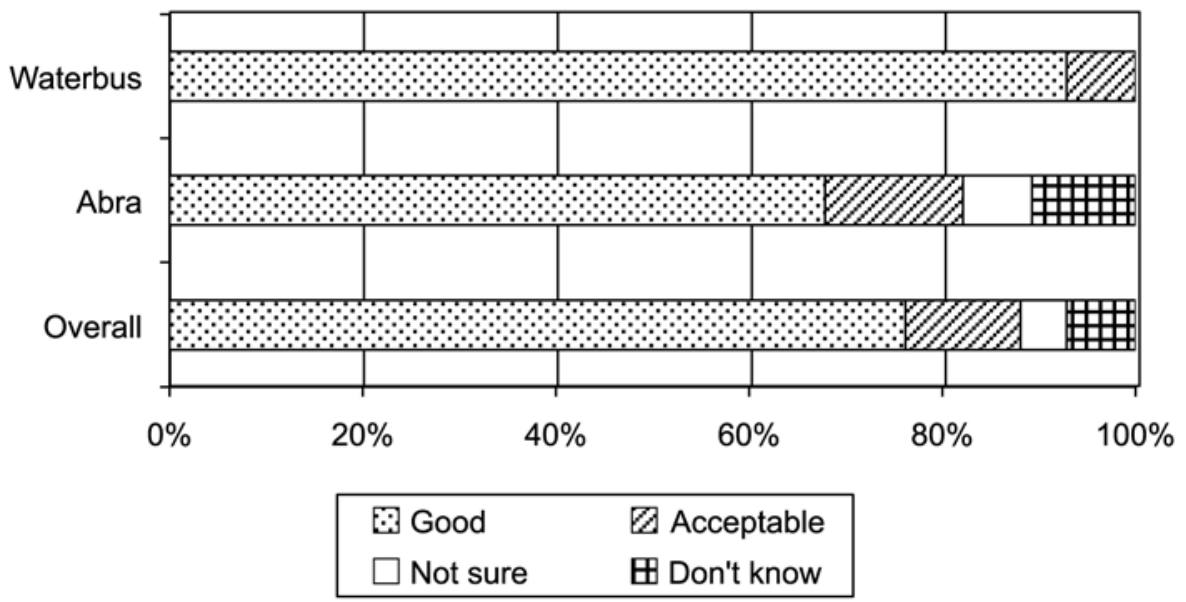

Figure 16. Level of Service and Safety of Marine Vessels Indicated by Operators 
With regard to what measures to implement to make the marine service more attractive to users (Figure 17), adding newer stations (39\%), increasing the frequency of operation (19\%), and increasing the comfort level (19\%) were indicated. On the other hand, operators suggested more frequent updates to roster and operator schedules (47\%) and decreasing the service span time (29\%).

\begin{tabular}{|l|c|}
\hline $\begin{array}{c}\text { How can marine service be } \\
\text { attractive to users? }\end{array}$ & $\begin{array}{c}\text { How can marine service be } \\
\text { attractive to operators? }\end{array}$ \\
\hline
\end{tabular}

Figure 17. Measures to Increase Attractiveness of Service (Users and Operators) 


\section{Additional Discussion of Survey Findings}

From the user survey, trip fare was found to be the most important criteria for service effectiveness (see Figure 9). Respondents also suggested a reduction in fare for Waterbus service. Some Abra users showed interest in shifting to Waterbus if the price were reduced by 50 percent. Ahmed et al. (2009) investigated the price elasticity of Waterbus in Dubai and found it to be elastic. This means that a reduction in the trip fare would increase revenue earnings.

Currently, there is no database of the marine transport system except collected records of monthly passenger counts. Establishing a database for the marine transport system could assist in better planning, operational, and management aspects of the system. The database platform could be such that it can support GIS analysis. For example, the authority can use GIS technology to manage routes, define locations to establish new stations, define influence/catchments areas of each station, prioritize routes based on demand, etc. Furthermore, interaction with Google maps can help users choose the routes and plan their journey in advance.

During the study, the authors observed a deficiency of quality waiting areas and toilet and wash facilities in the stations. This point also was raised by some respondents (users and operators). Users also indicate some difficulties with intermodal connectivity to and from the marine stations, especially by bus. Improving these conditions could increase the ridership of current users and may encourage nonusers to start using the marine services.

As previously indicated, one of the limitations of this study was the exclusion of non-users or prospective users in the survey process. A further study should be conducted to identify prospective users and find means to increase the ridership of the marine services. Nonetheless, from the results collected in this study and the above discussion, the following improvements are suggested:

- Consideration should be given to reducing the service fare for Waterbus. This service may earn more revenue by reducing the fare.

- The level of comfort for users should be enhanced by providing better facilities at stations, including better shading and air-conditioned waiting locations, toilets, and washrooms.

- A database for the marine transport system should be developed that could be used for planning, operational, and management purposes. The database platform should support GIS analysis. 
- Initiatives should be undertaken by MA-RTA to develop a good intermodal connectivity to and from the marine stations, including public bus stops near stations, more bus routes with good frequency, and more parking spaces for private cars.

\section{Conclusion}

The majority of assessment tools for the operation practice of MA-RTA services indicated quite acceptable levels of services. Nonetheless, some areas of deficiencies exist. Success of MA-RTA services requires adequate planning and maximization of linkage and connectivity among marine services and land public transport facilities. While MA-RTA services might not be profitable, they are a critical sector in complementing all other RTA services. In this perspective, business opportunities of MA-RTA services should be looked at as those that could help reduce the "marginal" cost on all existing transport services (i.e., marine and land services). A profitable project is the one whose capital cost plus long-run operational costs are compromised by the profit of the service itself as well as the overall reductions in (direct and indirect) costs among all other modes of transportation.

\section{Acknowledgment}

This research was funded by the MA-RTA project number MR014. The authors would like to acknowledge the efforts of Farida Yaqoob, Hussain Al Saffar, and Sarah Mohammad of MA-RTA for their valuable contributions and feedback throughout the study.

\section{References}

Ahern, A. A., and N. Tapley. 2008. The use of stated preference techniques to model modal choices on interurban trips in Ireland. Transportation Research Part A 42: 15-27.

Ahmed F., Y. E., Hawas, M. Hassan, M. Maraqa, and M. B. Khan. 2009. A framework for the assessment and policy development of the water-transit services in Dubai, UAE, submitted to Journal of Public Transportation.

Ceder, A. 2006. Planning and evaluation of passenger ferry service in Hong Kong, Transportation, 33(2), 133-152. 
Dunlop G. 2002. The European ferry industry: Challenges and changes. International Journal of Transport Management 1(2): 115-116.

Espino, R., J. De D. Ortu'zar, and C. Roma'n. 2007. Understanding suburban travel demand: Flexible modelling with revealed and stated choice data. Transportation Research Part A 41: 899-912.

Lai, M. F., and H. K. Lo. 2004. Ferry service network design: Optimal fleet size, routing and scheduling, Transportation Research Part A 38(4): 305-328.

MBTA. 2006. Service Delivery Policy. Massachusetts Bay Transportation Authority.

Melissa, M. L., and G. D. Michael. 2007. Ferry service market analysis: National Parks of New York Harbor. Transportation Research Record 1793: 99-105.

Miller, I. R., J. W. Freund, and R. Johnson. 1990. Probability and Statistics for Engineers, 4th edition. Prentice Hall Inc., New Jersey.

Odeck, J., and S. Brathen. 2009. The efficiency of Norwegian ferries in providing public transport services. International Journal of Transport Economics 36(1): 121-139.

Outwater, M. L., S. Castleberry, Y. Shiftan, M. Ben-Akiva, Y. S. Zhou, and A. Kuppam. 2003. Attitudinal market segmentation approach to mode choice and ridership forecasting: Structural equation modeling. Transportation Research Record 1854: 32-42.

Pickrell, S., and L. Neumann. 2000. Use of performance measures in transportation decision making. In Performance Measures to Improve Transportation Systems and Agency Operations, Transportation Research Board, Irvine, California.

Polak, J., and P. Jones. 1995. Using stated-preference methods to examine traveler preferences and responses. In Understanding Travel Behaviour in an Era of Change, eds. P.R. Stopher and M.E.H. Lee-Gosselin, Pergamon-Elsevier, Oxford.

Russell, S. E., and V. A. Eugene. 1999. Intermodal ferry terminal master plans for Washington State Ferries: Planning for the future. Transportation Research Record 1677: 105-116.

Wilson, B. 2005. Waterborne transit: On the move in Southeast Florida. Transportation Planning 30(1): 6-7. 


\section{About the Authors}

Mohammad NuRUl HASSAN (mnhassan@uaeu.ac.ae) is a research assistant at the Roadway, Transportation and Traffic Safety Research Center (RTTSRC) at UAE University. He has an M.Sc. degree in Urban and Regional Planning from Bangladesh University of Engineering and Technology. His research focuses on land use and transport planning and policy.

YASER E. HAwAS (y.hawas@uaeu.ac.ae) currently serves as a professor in the Department of Civil and Environmental Engineering at UAE University, where he also serves as Director of the RTTSRC. He obtained his Ph.D. from the Civil Engineering Department at the University of Texas at Austin in 1996 and joined UAE University in 1998. He has published more than 40 international journal and conference papers and has carried out several professional studies and consultancy works for local and international agencies including the Texas Department of Transportation (US), the Federal Highway Administration, Holden Vehicle Manufacturers (Australia), the United Nations (ESCWA), and many others in the UAE.

MUNJED MARAQA (m.maraqa@uaeu.ac.ae) is an associate professor in the Department of Civil and Environmental Engineering at the UAE University. He has a Ph. D. degree in Environmental Engineering from Michigan State University. His research focuses on mass transfer in porous media. He also is associated with the RTTSRC at UAE University and maintains a research interest in environmental issues associated with transportation.

FAISAL Ahmed (faisal_ahmed@uaeu.ac.ae) is a research assistant at the RTTSRC at UAE University. He obtained his M. Sc. degree in Civil Engineering from Chalmers University of Technology (CTH) in Sweden. His research focuses on traffic engineering, transport planning, and ITS.

MD BAYzid KhAN (md_bayzid@uaeu.ac.ae) is an M. Sc. student and a research assistant at the RTTSRC at UAE University. He has a B.Sc. degree in Urban and Regional Planning from Bangladesh University of Engineering and Technology and a keen interest in GIS applications in transport planning and accident research. 